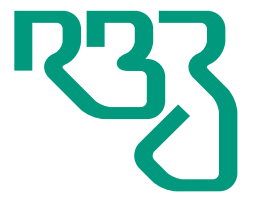

\section{Revista}

Brasileira de

Zootecnia

Brazilian Journal of Animal Science

ISSN 1806-9290

www.rbz.org.br

\title{
Macroscopic embryonic development of Guinea fowl compared to other domestic bird species
}

\author{
Itallo Conrado Sousa de Araújo $^{1^{*}}$ iD, Luana Rudrigues Lucas ${ }^{2}$, Juliana Pinto \\ Machado $^{3}$ (iD, Mariana Alves Mesquita ${ }^{3}$ \\ ${ }^{1}$ Universidade Federal de Minas Gerais, Escola de Veterinária, Departamento de Zootecnia, \\ Belo Horizonte, MG, Brasil. \\ 2 Faculdade de Ciências da Saúde de Unaí, Faculdade de Veterinária, Unaí, MG, Brasil. \\ ${ }^{3}$ Universidade Federal de Goiás, Programa de Pós-graduação em Zootecnia, Goiânia, \\ GO, Brasil.
}

\author{
*Corresponding author: \\ italloconradovet@hotmail.com \\ Received: March 28, 2019 \\ Accepted: August 25, 2019 \\ How to cite: Araújo, I. C. S.; Lucas, L. R.; \\ Machado, J. P. and Mesquita, M. A. 2019. \\ Macroscopic embryonic development of Guinea \\ fowl compared to other domestic bird species. \\ Revista Brasileira de Zootecnia 48:e20190056. \\ https://doi.org/10.1590/rbz4820190056 \\ Copyright: This is an open access article \\ distributed under the terms of the \\ Creative Commons Attribution License \\ (http://creativecommons.org/licenses/by/4.0/), \\ which permits unrestricted use, distribution, \\ and reproduction in any medium, provided the \\ original work is properly cited.
}

\begin{abstract}
Since few studies have addressed the embryonic development of Guinea fowl (Numida meleagris), the objective of the present study was to evaluate its embryonic development in the Cerrado region of Brazil and compare the results to published descriptions of the embryonic development of other domestic bird species. The commercialized weight for Guinea fowl eggs used in the experiment was found to be $37.57 \mathrm{~g}$, while egg fertility was $92 \%$. Embryo growth rate (\%) was higher on the sixth day of incubation relative to other days. The heart began beating on the third day of development, while eye pigmentation and upper and lower limb buds appeared on the sixth day. The yolk sac was incorporated on the 24 th day followed by chick external pipping and hatching on the 28th day. Comparisons revealed that the embryonic development of Guinea fowl exhibits both similarities to, and differences from, the embryonic development of other domestic birds. From three days of embryonic development, differences were observed among the compared species. Despite the same incubation period, Guinea fowl embryos develop faster than turkeys. All species begin internal pecking two days before hatching and internal pecking $24 \mathrm{~h}$ before hatching.
\end{abstract}

Keywords: embryo, fertile eggs, Gallus gallus domesticus, Numida meleagris

\section{Introduction}

Guinea fowl (Numida meleagris) is a native bird of West Africa. It was first brought to Brazil by Portuguese settlers in the 15th century, where it continues to persist as an exotic species (Menezes et al., 2001). The birds were popular in Brazil because of their rustic nature and adaptability to the climate and were given different names in the different regions of the country where they were reared, such as "Guinea fowl", "capote", "Angola", “angolinha", "pintada”, and "tô-fraco" (Mallmann et al., 2001).

Guinea fowl is intensively produced in countries such as France, while the production of eggs and meat are popular in Italy, Belgium, and Scandinavian countries. It is even classified as the second greatest source of poultry meat and eggs, after the domestic chicken, in these European countries (Bernacki et al., 2013). The production of Guinea fowl in Africa has traditional cultural significance, while in Brazil it is produced for both the consumption of its meat and eggs and as a hobby (Konlan et al., 2011).

Despite the popularity of Guinea fowl production in European and African countries, its production in Brazil can be improved, because poultry raised in intensive systems produce higher-quality meat than that of other highly regarded poultry, such as pheasants (López-Pedrouso et al., 2019). Guinea 
fowl meat stands out for its finesse and taste relative to that of turkeys, ducks, and chickens. Some characteristics of Guinea fowl have been improved in recent years, resulting in greater weight gain and increased egg laying, although smaller eggs are produced relative to common hens (Madeira, 2011).

One of the most well known characteristics of Guinea fowl is that they are overly energetic birds that become easily stressed. This may explain their low maternal ability and why their eggs require artificial incubation or incubation by domestic chickens (Mallmann et al., 2001). Research into Guinea fowl reproduction has been limited and, thus, their genetic improvement has been delayed compared with that of chickens, ducks, turkeys, and quail.

Therefore, artificial incubation of Guinea fowl eggs is considered an important step in the development of their production in Brazil, both on industrial and local scales. Reported hatching rates for Guinea fowl vary widely ( 45 to 86\%) (Bernacki et al., 2013; Yamak et al., 2015), suggesting potential for optimizing the hatching process to replenish flocks and increase production. Information on Guinea fowl hatching is scarce, with most studies being performed in temperate countries, which limits their relevance for Guinea fowl production in Brazil.

Thus, the objective of the present study was to investigate the macroscopic embryonic development of Guinea fowl in Cerrado region, northwestern Minas Gerais State, Brazil, and compare it with the embryonic development of other domestic birds.

\section{Material and Methods}

The local Ethics Committee for Animal Research approved the experimental protocol (case no. $004 / 2016)$. This study was conducted in the city of Unaí, Minas Gerais, Brazil $\left(16.3596^{\circ} \mathrm{S}, 46.9025^{\circ} \mathrm{W}\right)$.

A total of 330 eggs were collected from two points of commerce (115 each) in the informal market of the city of Unaí, aiming at obtaining eggs from several farms that raise what are considered free-range Guinea fowl. Eggs were collected $24 \mathrm{~h}$ prior to commercialization, stored at ambient temperature $\left(27^{\circ} \mathrm{C}\right)$, and then stored in a cool environment $\left(14^{\circ} \mathrm{C}\right)$ for $48 \mathrm{~h}$. The Guinea fowl breeders that produced the eggs were between 28 and 34 weeks of age. After storage, 100 eggs were broken to evaluate fertility by visual identification of the germinative disk. The fertility rate of the analyzed eggs was $92 \%$.

A total of 175 eggs were then enumerated, weighed $( \pm 37.57 \mathrm{~g}$ ), and placed in an incubator (Premium Ecológica ${ }^{\circledR}$ ) with a capacity for 180 eggs. The incubator was set to maintain a temperature of $37.2{ }^{\circ} \mathrm{C}$ $\left( \pm 1{ }^{\circ} \mathrm{C}\right)$, relative humidity of $60 \%$, and continuous ventilation while turning the eggs every $2 \mathrm{~h}$. Incubation was monitored daily, and after 26 days, the machine was set to a temperature of $36.2^{\circ} \mathrm{C}$ and relative humidity of $70 \%$, while turning was interrupted.

Macroscopically embryonic development was monitored for 28 days at the same time ( $18.00 \mathrm{~h}$ ) everyday by evaluating the embryonic constituents of six randomly chosen eggs. Embryos were deposited in a petri dish and measured with an acrylic ruler. After eight days of development, size was measured as the length from the tip of the beak to the tip of the middle toe (discounting the nail). Digital photos of all embryos were taken with a Samsung Galaxy J5 mobile phone with 32-megapixel resolution. All structures observed external to embryos were recorded prior to the embryos being euthanized for the identification of internal structures. Data were recorded in a spreadsheet including the assignment of developmental stage and any structures present in the embryo.

\section{Results}

The studied eggs were rounded, more pointed at the narrow end, and light brown in color with a mean weight of $37.57 \mathrm{~g}$ (Figure 1). Images obtained at all stages of embryonic development are presented in Figure 2. During the first $24 \mathrm{~h}$ of incubation, there was an evident appearance of the zona pellucida. 


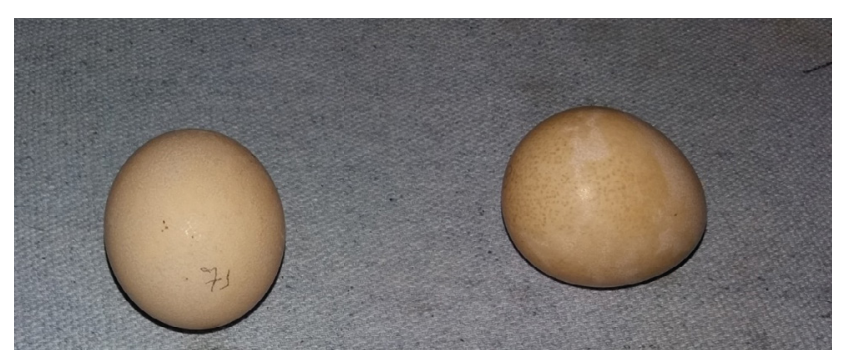

Figure 1 - Guinea fowl (Numida meleagris) eggs from Brazil.

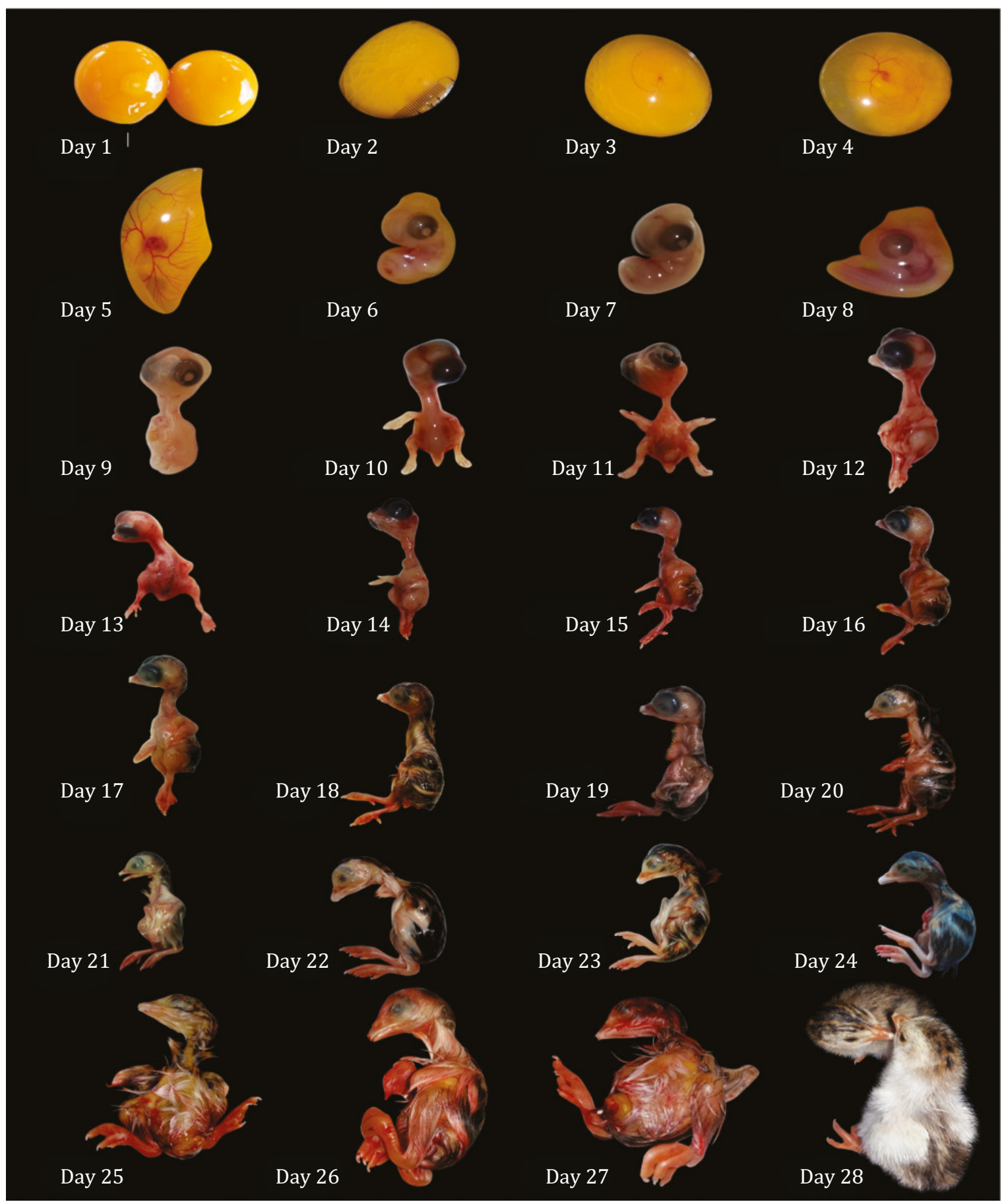

Figure 2 - Macroscopic embryonic development of Guinea fowl (Numida meleagris). 
After $48 \mathrm{~h}$ of incubation, angiogenesis and the presence of blood vessels were evident. At $72 \mathrm{~h}$ of development, the heart was observed beating and causing blood circulation.

The fourth day of development revealed an increase in the size of heart, while the embryo had a " $\mathrm{C}$ " shape, still with visible optic vesicles. Formation of the amnion, eyes, and spine and the appearance of lower and upper limb buds were observed at five days of development. The sixth day of development revealed the formation of the brain cap and evidence of black eyes.

The amnion and allantois were evident on the seventh day with initial formation of the beak. The eighth day of embryonic development revealed formation of the beak in all six embryos analyzed, as well as a clearly evident heart, traces of the ocular vesicle, the beginning of oral cavity formation, developed limbs, black eyes, digits on feet and wings, and the beginning of bone cartilage formation and chorio-allantois development. The presence of the beak was more evident on the ninth day, along with the presence of digits of the upper and lower limbs and, when the abdominal cavity was opened, the onset of liver formation.

On the 10th day, the presence of the beak, tail, and feet and the beginning of nostril formation were evident externally, while internally, the formation of the pro-ventricle and liver and the presence of the intestine and heart with cavities were apparent. On the 11th day, the formation of the beak diamond (egg tooth) and digits of the feet and wings were evident, as were the cloaca and the formation of the oral cavity. Eyelids appeared and feather follicles were visible on back and thighs.

The 12th day of incubation revealed the accelerated development of the viscera, cartilaginous rings in the trachea, and presence of eyelids and an extended abdomen. On the 13th day, the follicles and feathers were more evident and distributed on the thighs, back, and neck with presence of first feathers on the back. Also apparent were the formation of the yolk pendulum, intestine, and auditory canal and the presence of the tongue.

On the 14th day of incubation, it was possible to detect the presence of feathers and nails on the digits of the wings and feet. It was also possible to observe the crop and calcification of cartilage. The 15th day revealed evident nostrils, head proportional to the body, well differentiated nails, and an increase in the number of feathers, mainly in the cervical and dorsal regions. The 16th day brought a significant increase in the number of feathers, well developed interdigital membranes and sewer, scales on the feet, and evident nostrils, while the 17th day revealed scales on the feet, feathers of different colors, and a well-formed gut. On the 18th day of embryonic development, there was a significant increase in the number of feathers, while on 19th day, developed ears were present. The 20th day revealed a denser embryonic bundle, while on the 21st day, there was a full embryo.

From the 23rd to the 25th day, the yolk sac became almost completely inserted in the abdominal cavity, while on the 25th day, the chick started to turn towards the air chamber of the egg. The almost complete incorporation of the yolk sac was observed on the 25th day, along with an open navel, while the embryo totally occupied the egg with the exception of the air chamber. Still, the embryo turned its body to the correct position: a folded neck and head under the air space membrane, position of the head under the right wing. On the 26th day, inner shell membrane was pierced. Such neck folding was maintained after both internal and external pipping and until the chick escaped from the shell once hatching was complete. The 27th day brought the total incorporation of the yolk sac (closed navel) and initiation of the rupture of the external eggshell. At that moment, it was possible to observe the vocalization of the chicks inside the egg.

The 28th day, the last day of embryonic development, brought breakage of the eggshell (hatching). Normally born chicks had hydrated, dried feathers that varied in color (gray, white, and brown), exhibiting the characteristic coloration of the species. Guinea fowl chicks have beak and orange feet, were active, and had a fully healed navel. A comparative table presents the main characteristics of the embryos in each of the studied days and compares them with chickens, Pequin ducks, and turkeys (Table 1). 
Table 1 - Chronological development of Guinea fowl compared with chicken (Gallus gallus domesticus), Pequin duck (Anas boschas), and turkey (Meleagris gallopavos) for optimal incubation conditions

\begin{tabular}{|c|c|c|c|c|c|}
\hline & & Numida meleagris & $\begin{array}{l}\text { Gallus gallus } \\
\text { domesticus }^{1}\end{array}$ & $\begin{array}{c}\text { Anas } \\
\text { boschas }^{2}\end{array}$ & $\begin{array}{r}\text { Meleagris } \\
\text { gallopavos }\end{array}$ \\
\hline Day & $\begin{array}{c}\text { Length } \\
(\mathrm{mm})\end{array}$ & Main characteristic & Day & Day & Day \\
\hline 1 & 1.3 & The zona pellucida & 1 & 1 & 1 \\
\hline 2 & 2.3 & Angiogenesis and the presence of blood in blood vessels & 2 & 2 & 2 \\
\hline 3 & 4.0 & Heart is observed beating and causing blood circulation & 2 & 4 & 3 \\
\hline 4 & 4.8 & Optic vesicles & 2 & 4 & 3 \\
\hline 5 & 5 & Appearance of lower and upper limb buds & $3-5$ & 6 & - \\
\hline 6 & 6.5 & Evidence of black eyes & 5 & 6 & 5 \\
\hline 7 & 14.1 & Amnion and allantois are evident & 7-7.5 & 9 & - \\
\hline 8 & 20.2 & Chorio-allantois begins to develop; initial formation of the beak & 6 & 9 & 10 \\
\hline 9 & 27.2 & Presence of digits of the upper and lower limbs & $7-7.5$ & 11 & 9 \\
\hline 10 & 33.2 & Nostril formation & 10 & 12 & - \\
\hline 11 & 42.6 & $\begin{array}{l}\text { Distinct egg tooth; eyelids appear; feather follicles visible on } \\
\text { back and thighs }\end{array}$ & 7 & 11 & 11 \\
\hline 12 & 45.7 & Upper beak begins to protrude beyond lower beak in & 9 & 10 & 10 \\
\hline 13 & 52.0 & First feathers & 10 & 17 & 17 \\
\hline 14 & 55.7 & Feathers and nails on the digits of the wings and feet & 11 & 14 & 15 \\
\hline 15 & 68.3 & $\begin{array}{l}\text { Increase in the number of feathers, mainly in the cervical and } \\
\text { dorsal regions }\end{array}$ & 12 & 19 & 17 \\
\hline 16 & 70.6 & Scales on the feet & 14 & 18 & 15 \\
\hline 17 & 78.0 & Feathers of different colors & - & - & - \\
\hline 18 & 88.0 & Full embryo formation & 17 & 21 & 21 \\
\hline 19 & 89.0 & Growth phase & - & - & - \\
\hline 20 & 99.2 & Growth phase & - & - & - \\
\hline 21 & 106.7 & Growth phase & - & - & - \\
\hline 22 & 111.4 & Growth phase & - & - & - \\
\hline 23 & 114.5 & Yolk sac begins being inserted in the abdominal cavity & 19 & 25 & 25 \\
\hline 24 & 117.5 & - & - & - & - \\
\hline 25 & 122.0 & $\begin{array}{l}\text { Yolk sac becomes almost completely inserted in the abdominal } \\
\text { cavity; open navel }\end{array}$ & 20 & 26 & 27 \\
\hline 26 & 126.9 & Inner shell membrane is pierced & 19 & 26 & 26 \\
\hline 27 & 132.2 & Shell pipped; closed navel & 20 & 27 & 27 \\
\hline 28 & 134.1 & Hatching & 21 & 28 & 28 \\
\hline
\end{tabular}

${ }^{1}$ Hamburger and Hamilton (1951).

${ }^{2}$ Pereira (2014).

${ }^{3}$ Aviagen Turkeys (2006)

\section{Discussion}

The mean weight of the studied Guinea fowl eggs (37.57 g) was lower than that of eggs of dams of meat-type breeders of French Guinea fowl (55.3 g), but closer to that of domestic African Guinea fowl (40.7 g) (Nowaczewski et al., 2008). Certainly, the greater weight of the eggs of commercial strains used in other countries is due to past genetic selection, with wild and free-range birds having lower egg weight. Indeed, the weight of Guinea fowl eggs is lower than that of commercial hen eggs. According to Araújo Netto et al. (2018), the average weight of brown laying hen eggs is $54.6 \mathrm{~g}$, which is about $17.0 \mathrm{~g}$ heavier than Guinea fowl eggs of the present study. 
Guinea fowl eggs differ from those of other domestic species with regard to their shape and size, being more rounded and more pointed at the lower end (Gilbert, 2013). Guinea fowl eggs appear similar to those of collar pheasants (Figure 1) and have a similar average weight (34.25 g) (Uğurlu et al., 2017), although the pheasant eggs are browner.

The zona pellucida appeared during the first $24 \mathrm{~h}$ of incubation. According to Sellier et al. (2006), the embryonic development of broiler chickens, turkeys, domestic ducks, and Guinea fowls do not differ during the first $48 \mathrm{~h}$, with the embryos appearing practically identical. The heartbeat of Guinea fowl embryos begins at three days of development. According to Brake et al. (2011), the heartbeat of broiler embryos begins at two days of development, while that of Pekin ducks ( $A$. boschas) and turkeys (M. gallopavos) begins at four days of embryonic development (Pereira, 2014; Aviagen Turkeys, 2006). The heartbeat of quail embryos begins at two days (Ainsworth et al., 2010). Therefore, broiler chicken embryos have a faster metabolism, since the period of embryonic development is one week shorter than that of Guinea fowls, and their heart begins beating one day earlier.

According to Brake et al. (2011), pigmentation of the eye of broiler embryos begins on the fourth day of development, while that of the Pekin ducks (Pereira, 2014) and Guinea fowls begin on the sixth day, and that of turkeys on the fifth day (Aviagen Turkeys, 2006). Limb buds of broiler embryos appear later, at eight days of embryonic development (Brake et al., 2011).

The increase of the blastoderm and by the successive appearance of the so-called extra-embryonic membranes yolk sac, amnion, and beginning of allantois occurs in the first days ( 0 to 5 ). The end of this period corresponds to stage 21 of Hamburger and Hamilton (1951).

The formation of the beak begins on the tenth day of development in turkeys (Aviagen Turkeys, 2006), while on the sixth day in chickens (Brake et al., 2011) and on the ninth day in Pekin ducks (Pereira, 2014), with the formation of the beak of the last being most like that of Guinea fowls. The proper development of the embryonic beak is fundamental for successful hatching and feeding for broilers. According to García (2007), the beak diamond, called the egg tooth, is a small conical-shaped protuberance composed of keratin that is located on the maxilla of some oviparous vertebrates, and is used to break egg membranes during hatching.

Pereira (2014) reported that the beginning of nail formation in embryos of Pekin ducks can be observed on the 14th day of incubation, while the presence of nostrils and head and body of the embryo in the same proportion occur on the 15th day, which is similar to that of Guinea fowl embryos. According to the author, full embryo formation occurs on the 21st day of incubation in Pekin ducks, while for Guinea fowls, it takes place on the 18th day.

Pereira (2014) also affirmed that yolk sac incorporation begins on the 25th day of incubation for Pekin ducks, while it occurs on the 19th day for broiler chickens (Barbosa, 2011) and on the 25th day for turkeys (Aviagen Turkeys, 2006). These species differ from Guinea fowl, in which the yolk sac is incorporated on the 23rd day of embryonic development (Figure 2).

According to Barbosa (2011), chicken eggs hatch on the 21st day of incubation, while Pereira (2014) reported that Pekin duck eggs hatch on the 28th day, as do turkey eggs (Aviagen Turkeys, 2006).

Daily measurements of embryo size revealed that embryonic growth of Guinea fowls is linear (Figure 3), which is also true for broiler chickens, Peking ducks, and turkeys (Warin, 2006; Pereira, 2014; Aviagen Turkeys, 2006; Brake et al., 2011). Guinea fowl embryos are smaller than chicken, turkey, and Pekin duck embryos from the first day of incubation until the newly hatched chick, and are even smaller than birds with the same incubation period. According to Araújo et al. (2016), egg weight is a determinant of newborn chick size, which explains the smaller size of Guinea fowl embryos relative to the other fowl species discussed here.

Dupuy et al. (2002) argued that, although chicken and mallard embryos have similar morphological characteristics, the absolute development rate differs between these birds. The comparison of the present study with that of Pekin ducks (Pereira, 2014) shows that although they share many morphological characteristics in the same period of embryonic development, Guinea fowl show 


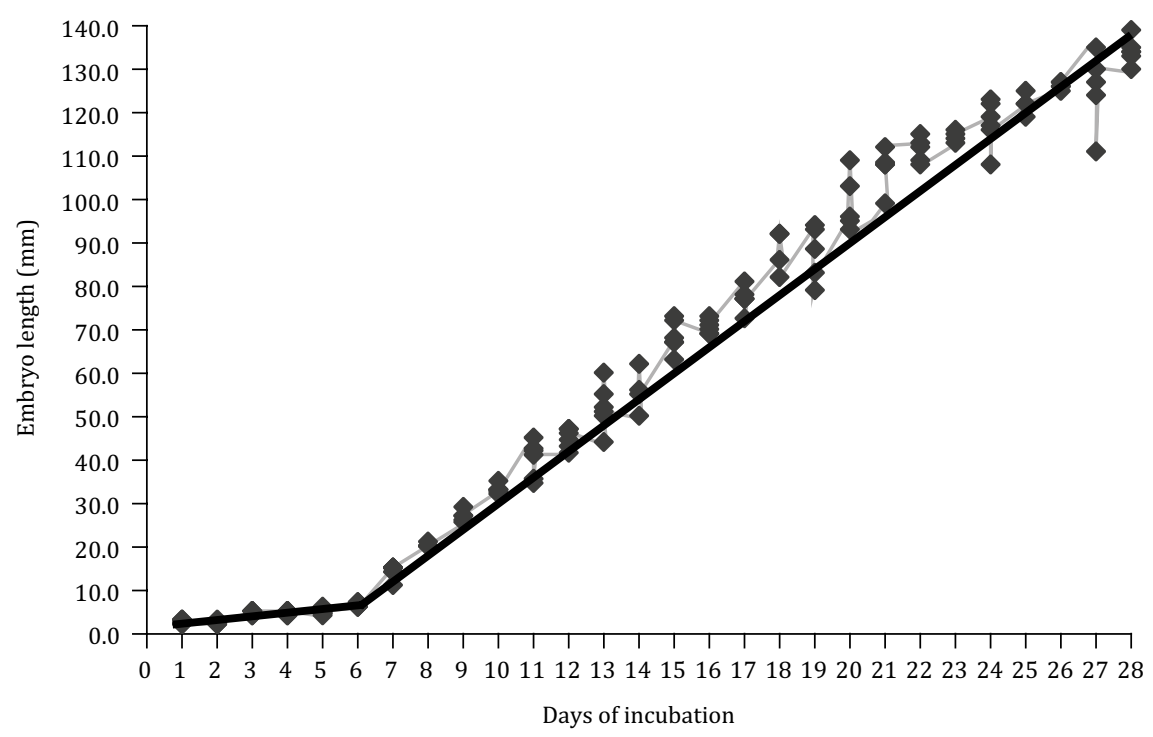

Figure 3 - Length of Guinea fowl embryos from 1 to 28 days of incubation ( $\left.Y=5.5523 x-17.1992 ; R^{2}=0.9725\right)$.

a higher rate of embryonic growth in the first five days. For embryo length, there was a uniform behavior up to five days; from six days onwards, it presented an increasing linear effect of $5.5 \mathrm{~mm}$ per day $\left(\mathrm{R}^{2}=0.9725\right)$.

Over the last decade, there has been a growing interest in meat from Guinea fowl and other non-conventional birds. The consumption of traditional meat at this time shows a low growth, and consumers are looking for other alternative types of meat (López-Pedrouso et al., 2019). Understanding the process of embryo development of Guinea fowl can improve the production rates of chicks and, thus, increase the supply of meat to the population.

\section{Conclusions}

It is possible to conclude that, although embryonic development is morphologically similar among the poultry compared herein, during the first $48 \mathrm{~h}$ of development, there are no differences observed macroscopically for the development of Guinea fowl in relation to chicken, Pekin duck, and turkey. From 3 to 25 days, there are several differences. Despite the same incubation period, Guinea fowl embryos show a more rapid development than turkeys. All species do the internal pipping two days before hatching and the external pipping of the hull $24 \mathrm{~h}$ before hatching.

\section{Conflict of Interest}

The authors declare no conflict of interest.

\section{Author Contributions}

Conceptualization: I.C.S. Araújo and J.P. Machado. Investigation: I.C.S. Araújo and L.R. Lucas. Resources: L.R. Lucas. Writing-original draft: I.C.S. Araújo and M.A. Mesquita. Writing-review \& editing: I.C.S. Araújo and M.A. Mesquita.

\section{Acknowledgments}

The authors acknowledge the assistance of the Pró-Reitoria de Pesquisa of the Universidade Federal de Minas Gerais (UFMG) for providing funds for publication. 


\section{References}

Ainsworth, S. J.; Stanley, R. L. and Evans, D. J. R. 2010. Developmental stages of the Japanese quail. Journal of Anatomy 216:3-15. https://doi.org/10.1111/j.1469-7580.2009.01173.x

Araújo Netto, D.; Lima, H. J. D.; Alves, J. R.; Morais, B. C.; Rosa, M. S. and Bittencourt, T. M. 2018. Production of laying hens in different rearing systems under hot weather. Acta Scientiarum. Animal Sciences 40:e37677.

Araújo, I. C. S.; Leandro, N. S. M.; Mesquita, M. A.; Café, M. B.; Mello, H. H. C. and Gonzales, E. 2016. Effect of incubator type and broiler breeder age on hatchability and chick quality. Brazilian Journal of Poultry Science 18(spe.2):17-25. https://doi.org/10.1590/1806-9061-2015-0146

Aviagen Turkeys. 2006. Embryonic development. Lewisburg. Available at: <http://www.aviagenturkeys.us/ uploads/2015/12/18/(USA)AviagenTurkeyEmbryoPoster.pdf>. Accessed on: Sept. 20, 2019.

Barbosa, V. M. 2011. Fisiologia da incubação e desenvolvimento embrionário. 2.ed. FEP MZV, Belo Horizonte.

Bernacki, Z.; Kokoszynski, D. and Bawej, M. 2013. Laying performance, egg quality and hatching results in two guinea fowl genotypes. Archiv fur Geflugelkunde 77:109-115.

Brake, J. P.; Macklin, K. S.; Berry, W. D.; Voitle, R. A. and Hess, T. A. 2011. Chicken embryo development. Alabama Cooperative Extension System. p.1.

Dupuy, V.; Nersessian, B. and Bakst, M. R. 2002. Embryonic development from first cleavage through seventy-two hours incubation in two strains of pekin duck (Anas platyrhynchos). Poultry Science 81:860-868. https://doi. org/10.1093/ps/81.6.860

García, R. A. 2007. An "egg-tooth"-like structure in titanosaurian sauropod embryos. Journal of Vertebrate Paleontology 27:247-252. https://doi.org/10.1671/0272-4634(2007)27[247:AESITS]2.0.CO;2

Gilbert, A. B. 2013. Guinea fowl production: A guide for domestic \& wild guinea fowl enthusiasts. World's Poultry Science Journal 69:233-233. https://doi.org/10.1017/S0043933913000238

Hamburger, V. and Hamilton, H. L. 1951. A series of normal stages in the development of the chick embryo. Journal of Morphology 88:49-92. https://doi.org/10.1002/jmor.1050880104

Konlan, S. P.; Avornyo, F. K.; Karbo, N. and Sulleyman, A. 2011. Increasing guinea fowl eggs availability and hatchability in the dry season. Journal of World's Poultry Research 1:1-3.

López-Pedrouso, M.; Cantalapiedra, J.; Munekata, P. E. S.; Barba, F. J.; Lorenzo, J. M. and Franco, D. 2019. Carcass characteristics, meat quality and nutritional profile of pheasant, quail and Guinea fowl. p.269-311. In: More than beef, pork and chicken - The production, processing, and quality traits of other sources of meat for human diet. Lorenzo, J. M.; Munekata, P. E. S.; Barba, F. J. and Toldrá, F., eds. Springer, Cham. https://doi.org/10.1007/978-3-030-05484-7_10

Madeira, B. 2011. Galinhas de Angola: rusticidade, facilidade de criação e carne de excelência. Agrotec: Revista Técnico-Científica Agrícola (1):26.

Mallmann, A. J.; Szepaniuck, A. M.; Stertz, E. and Marmitt, L. A. 2001. Controle da broca da erva-mate através da galinha-d'Angola. Agroecologia e Desenvolvimento Rural Sustentável 2:13-17.

Menezes, R. C.; Mattos Jr, D. G.; Gomes, D. C.; Tortelly, R.; Muniz-Pereira, L. C. and Pinto, R. M. 2001. Trematodes of free range reared guinea fowls (Numida meleagris Linnaeus, 1758) in the state of Rio de Janeiro, Brazil: morphology and pathology. Avian Pathology 30:209-214. https://doi.org/10.1080/03079450124448

Nowaczewski, S.; Witkiewicz, K.; Frątczak, M.; Kontecka, H.; Rutkowski, A.; Krystianiak, S. and Rosiński, A. 2008. Egg quality from domestic and French guinea fowl. Nauka Przyroda Technologie 2:8-14.

Pereira, G. C. 2014. Desenvolvimento embrionário, rendimento da incubação e desempenho inicial de Marrecos-dePequim (Anas boschas). Dissertação (M.Sc.). Universidade Federal do Paraná, Curitiba.

Sellier, N.; Brillard, J. P.; Dupuy, V. and Bakst, M. R. 2006. Comparative staging of embryo development in chicken, turkey, duck, goose, Guinea fowl, and Japanese quail assessed from five hours after fertilization through seventy-two hours of incubation. Journal of Applied Poultry Research 15:219-228. https://doi.org/10.1093/japr/15.2.219

Uğurlu, M.; Akdağ, F.; Teke, B. and Salman, M. 2017. Effects of protein in diet and sex ratio on egg production, egg and hatching chick weight, fertility, hatchability and embryonal mortality in pheasants (Phasianus Colchicus). Brazilian Journal of Poultry Science 19:231-238. https://doi.org/10.1590/1806-9061-2016-0423

Warin, S. 2006. Embryonic development. Hatchery Expertise Online, n.7.

Yamak, U. S.; Boz, M. A. and Sarica, M. 2015. Changes in guinea fowl fertility and hatching traits over a 4-month laying season with long-term egg storage conditions. Indian Journal of Animal Research 49:532-536. https://doi.org/10.5958/0976-0555.2015.00124.7 